\title{
Radical-induced cationic frontal polymerisation for prepreg technology
}

\author{
Anh Dung $\operatorname{Tran}^{1} \cdot$ Thomas Koch $^{2} \cdot$ Robert Liska $^{1} \cdot$ Patrick Knaack ${ }^{1}[$
}

Received: 26 November 2020 / Accepted: 19 December 2020 / Published online: 23 January 2021

(c) The Author(s) 2021

\begin{abstract}
In this study, a new type of prepreg technology has been established using a dual curing system consisting of 1,6-hexanediol diacrylate (HDDA) and frontally polymerisable components based on the epoxide resin. The study of the polymerisation of HDDA revealed (tert-butylcyclohexyl)peroxydicarbonate (BCPC) as the most suitable radical thermal initiator. The presence of BCPC resulted in a fast radical polymerisation of HDDA and no cationic ring-opening reaction of the epoxy, which was observed by monitoring the double bond and epoxy group conversion in real time-NIR rheology measurement. The formed prepreg can subsequently be cured by radical-induced cationic frontal polymerisation of the epoxy resin. Effects of HDDA amount on the radical polymerisation, stiffness of the gel, frontal parameters and thermal mechanical properties of final polymers were investigated. With $10 \mathrm{wt} \% \mathrm{HDDA}$, the formed prepreg has very good storage stability, which was proved by monitoring the epoxy group conversion during 4 months of storage at $50{ }^{\circ} \mathrm{C}$ while still a stable front can be obtained. Furthermore, the RICFP-prepregs with different fibre contents were prepared and polymerised by RICFP. Then, a snowflake composite was successfully produced using RICFP-prepreg.
\end{abstract}

\section{Graphic abstract}

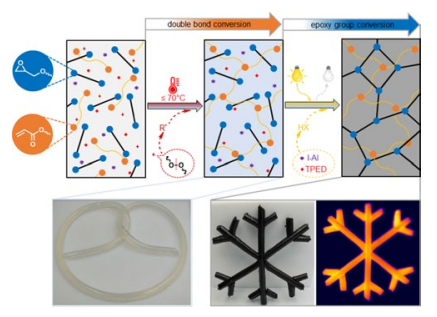

Keywords Polymerisations $\cdot$ Gels $\cdot$ Prepreg $\cdot$ Dual curing $\cdot$ Epoxy resins $\cdot$ Acrylates

\section{Introduction}

Supplementary Information The online version contains supplementary material available at https://doi.org/10.1007/s0070 6-020-02726-y.

Patrick Knaack

patrick.knaack@tuwien.ac.at

1 Institute of Applied Synthetic Chemistry, TU Wien, Getreidemarkt 9/E163-MC, 1060 Vienna, Austria

2 Institute of Materials Science and Technology, TU Wien, Getreidemarkt 9/E308, 1060 Vienna, Austria
Prepregs are semi-finished products consisting of fibres preimpregnated with a thermoplastic or thermosetting resin [1-3]. As an important matrix in fibre reinforced composites, epoxy resins are the most commonly used to produce prepregs [2, 4]. For manufacturing, the fibres are firstly impregnated with a low viscosity resin formulation. Afterwards, the resin is only partially cured to reach a viscous stage (so called B-stage) which prevents the resin flowing out of the fibres during storage and handling [1]. Because of their advantages in ready-to-use materials and outstanding properties of final products, epoxy-based prepregs are 
widely used in many applications, such as wind turbines [5-7], sports equipment [8], automotive [9, 10], aerospace [11-13], etc. Commonly, formulations for fibre pre-impregnation are based on components for thermally cured resins, with a hardener and accelerator if needed. Owing to the limited pot-life of these formulations, it is difficult to control the curing reaction at the so-called B-stage, which results in a very poor storage stability of the prepregs [1, 4]. In order to increase the stability, prepregs are normally stored at low temperatures e.g. $-18{ }^{\circ} \mathrm{C}$ right after their manufacturing $[1,14,15]$. There are also types that can be stored at room temperature, but they have to be cured then at even higher temperatures due to the lower reactivity of the resin formulations $[4,16-20]$.

Frontal polymerisation is a fast and energy-efficient process in which a localised polymerisation zone is initiated and moves through the whole monomer formulation [21-27]. Recently, a process called radical-induced cationic frontal polymerisation (RICFP) has been developed for bubble-free bulk curing of epoxy resins [28-32]. In RICFP, a three main component formulation consisting of an epoxy resin, a radical thermal initiator and a photoacid generator can be initiated thermally or under UV light irradiation. In the case of light initiation, the photoacid generator is decomposed and forms a super acid which starts cationic ring-opening polymerisation of the epoxy. The ring-opening reaction releases exothermic heat and then dissociates the radical thermal initiator to form radicals. Afterwards, these radicals interact with the photoacid generator in a redox reaction to liberate again the super acid and therefore keep the polymerisation spreading through the whole formulation without necessity of further irradiation [32]. With the presence of the radical thermal initiator, RICFP can also be initiated by external heat if it is higher than onset temperature of the polymerisation around $100{ }^{\circ} \mathrm{C}$ [33]. The previous works indicated that RICFP is not only a fast and energy-efficient process, but also the formulations have a long pot-life if stored in the dark [31, 33]. Furthermore, RICFP was successfully applied to produce epoxy-based composites with different types of fillers and fibres [28-30,34]. The composites with high content of fillers and good mechanical properties were produced within minutes by RICFP instead of hours thermal curing. With these advantages, in combination with the idea of having long pot-life formulations, a new type prepreg so called "RICFP-prepreg" should be established, which benefits in good storage stability, ready-to-use material and frontal polymerisability.

Our approach to prepare RICFP-prepregs is based on the classic prepreg manufacturing process. A low viscosity formulation is used to impregnate the fibres. Then, the formulation is pre-cured to form a highly viscous or sticky gel (B-stage). RICFP-prepregs should be storable at room temperature for several weeks to months without further curing as long as they are kept in the dark. In order to do this, a radically polymerisable monomer can be used in a mixture with a RICFP formulation. After impregnation of the fibres, the formulation is radically polymerised to form the B-stage. Later, RICFP is applied on demand to fully cure the epoxy monomers. For this approach, acrylates can be used as the radically polymerisable monomers. Depending on types of the radical initiator, the polymerisation of acrylates can be done by thermal or photo-curing $[35,36]$. Studies of a system consisting of acrylates and epoxy monomers were presented in different publications [37-40]. These works investigated interpenetrating networks which were formed via simultaneous polymerisation of the two monomers or sequential curing process. However, in preparation of RICFP-prepreg, the challenge is that the radical polymerisation process and the cationic ring-opening reaction needs to be separated. Furthermore, the radical initiators and polymerisation of acrylates should not affect the radical-induced cationic frontal polymerisation of the epoxy-based system.

In this study, a matrix formulation for preparation of RICFP-prepreg was investigated with 1,6-hexanediol diacrylate (HDDA) as a radically polymerisable monomer in a mixture with a frontal formulation based on epoxy resins. To form the B-stage, the radical polymerisation of acrylates was studied with different radical thermal initiators. A formulation consisting of BADGE as epoxy resin, (3-ethyloxetan-3-yl)methanol (EOM) as reactive diluent, 1,1,2,2-tetraphenylethane-1,2-diol (TPED) as radical thermal initiator and bis(4-tert-butylphenyl)iodonium tetrakis(perfluoro-tert-butyloxy)aluminate (I-Al) as photoacid generator was used for the radical-induced cationic frontal polymerisation. Gelation process was investigated for formulations with different weight ratios of acrylate and frontally polymerisable portions. Double bond and epoxy group conversion were followed using a real time near infrared spectroscopy during rheology measurement. Effects of acrylate portion on the frontal parameters, epoxy group conversion and thermal mechanical properties of the final polymers were also studied. As a crucial parameter in prepregs, storage stability of the gel was investigated. Furthermore, RICFP-prepregs were prepared with different contents of carbon fibre tow. Finally, for proof of concept, a snowflake structure, which should show the spread of the frontal polymerisation, was assembled from many prepreg segments and polymerised by RICFP. 


\section{Results and discussion}

\section{Study of radical thermal initiators for polymerisation of the acrylate monomer}

The aim of this study is to prepare a highly viscous or gelled B-stage which can be polymerised on demand by RICFP. Ideally, the gel should be formed by radical polymerisation of acrylates in a two-monomer formulation. Then, with the presence of the second cationic epoxide monomer formulation, the gel is polymerised by RICFP to form the final polymer. For this dual curing system, two radical thermal initiators are needed in the formulations. The first radical thermal initiator is used for the polymerisation of the acrylates while not effecting the RICFP system. The second is 1,1,2,2-tetraphenyl-1,2-ethandiol (TPED) for the radicalinduced cationic frontal polymerisation of the epoxide. The radical thermal initiator (RTI) for the polymerisation of acrylate monomers needs to meet requirements. Firstly, it should have decomposition and polymerisation temperatures lower than the onset temperature of the frontal polymerisation, otherwise the cationic reaction of the epoxy monomer will start. The temperature for the polymerisation of the acrylate should not be higher than $70{ }^{\circ} \mathrm{C}$. Secondly, during the polymerisation of the acrylates these radicals formed from the initiator should not undergo a redox reaction with the photoacid generators (PAGs) to form a super acid for cationic polymerisation of the epoxy monomers.

To find suitable radical thermal initiators (RTIs) for polymerisation of the acrylates, formulations were prepared with 1,6-hexanediol diacrylate (HDDA) and $2 \mathrm{~mol} \%$ of different radical initiators (AIBN, ACVA, BCPC, PODIC, KPS in Fig. 1). DSC measurements with a heating rate of $5{ }^{\circ} \mathrm{C} \mathrm{min}-1$ were performed for all these formulations. DSC plots from the measurements give information about the polymerisation temperature (onset temperature) and how fast the polymerisation occurs.

Figure 2 shows exothermic plots of the formulations containing HDDA (1,6-hexanediol diacrylate) with $2 \mathrm{~mol} \%$ of different radical thermal initiators. Information of the onset temperature and heat of the polymerisation are shown in Table S3 (Supporting information). It can be seen that the

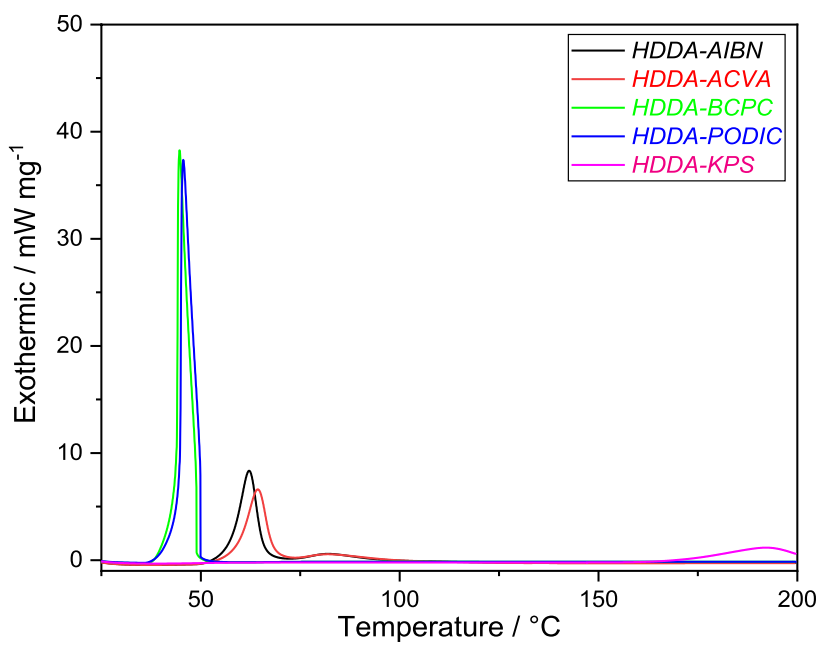

Fig. 2 DSC plots of formulations consisting of HDDA and $2 \mathrm{~mol} \%$ of different radical thermal initiators
Fig. 1 Acrylate monomer and different radical thermal initiators with their $10 \mathrm{~h}$ half-life temperature $\left(T_{1 / 2,10 \mathrm{~h}}\right)[41,42]$

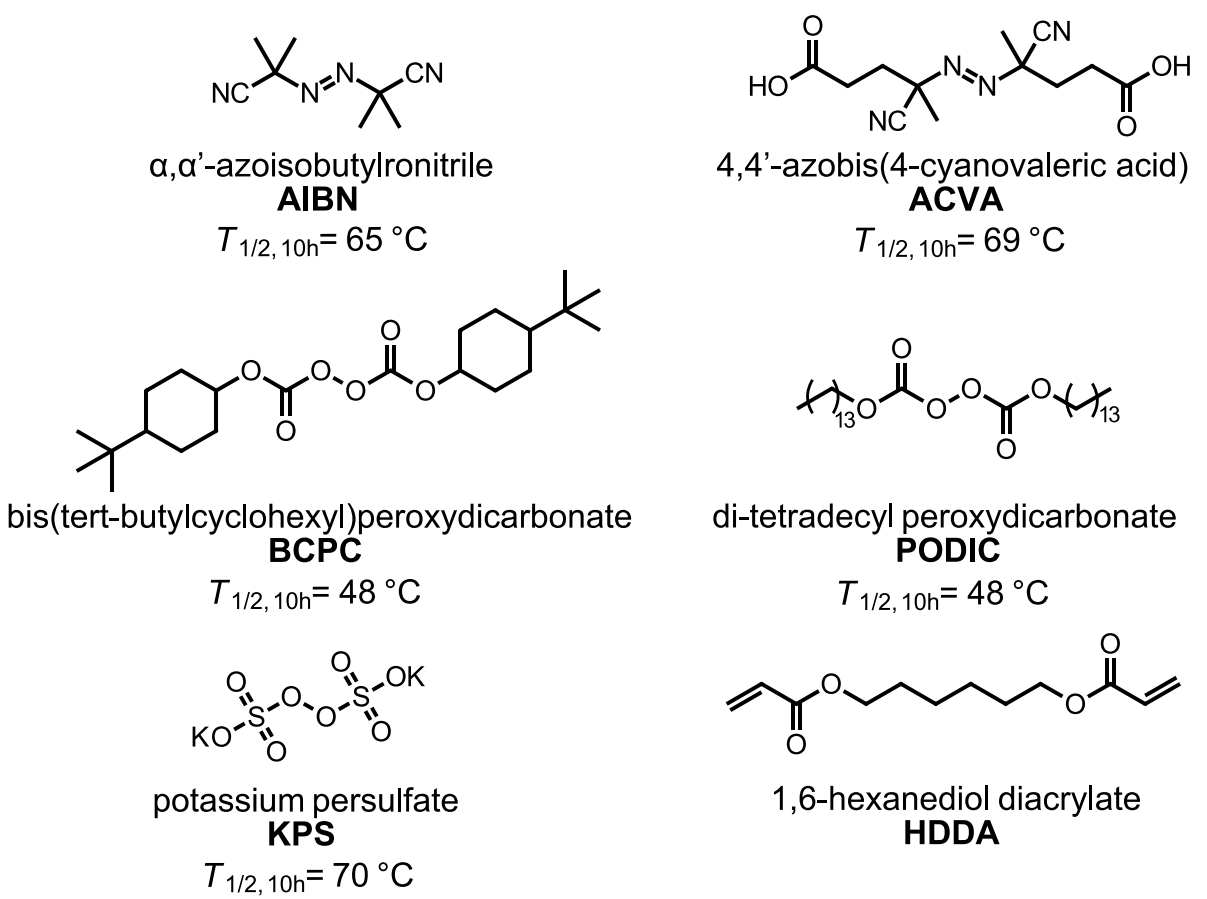


polymerisation of the formulations (except KPS) occurs at temperatures which are lower than $70{ }^{\circ} \mathrm{C}$. The formulations containing BCPC and PODIC are reacted at around $45^{\circ} \mathrm{C}$ which is lower than those of formulations with AIBN and ACVA (around $57^{\circ} \mathrm{C}$ ). The high and sharp exothermal peaks also indicate that the polymerisation obtained from the formulations containing BCPC and PODIC are faster, as compared to the other two formulations.

In addition, solubility of the initiators in HDDA was roughly checked by observing dissolution speed of the powders in the monomer. The observation indicates that BCPC and AIBN were easy and fast to dissolve in the monomer, while PODIC and ACVA were not. The PODIC based formulation was cloudy, while ACVA was precipitated from the solutions in about $10 \mathrm{~min}$ after mixing. In case of KPS, no dispersion could be observed. The precipitation occurred immediately after mixing. This explains the missing reaction peak on the DSC plot of the formulation containing KPS.

The above study indicates that BCPC seems to be the most suitable radical thermal initiator for the polymerisation of HDDA. In order to investigate the behaviour of BCPC in a system consisting of radical-induced cationic frontal polymerisable components (Fig. 3), an acrylate-epoxy formulation was prepared with $20 \mathrm{wt} \%$ radically polymerisable portion and $80 \mathrm{wt} \%$ frontally polymerisable portion. Composition of the radical polymerisable portion was the same as the formulation $H D D A-B C P C$ which includes $2 \mathrm{~mol} \%$ (3.5 wt \%) of BCPC in HDDA. The frontal polymerisation formulation (called $F P$ ) was prepared with BADGE and EOM ((3-ethyloxetan-3-yl)methanol) (with a molar ratio of 100:40, respectively), $2 \mathrm{~mol} \%$ (2.5 wt $\%$ ) TPED and $1 \mathrm{~mol} \%$ (4.6 wt\%) I-Al. Then, the acrylate-epoxy formulation is abbreviated to FP_20HDDA-BCPC. To observe the radical polymerisation of this formulation, DSC measurement was conducted in a temperature range of $25-200{ }^{\circ} \mathrm{C}$, with a heating rate of $1{ }^{\circ} \mathrm{C} \mathrm{min}^{-1}$. The same measurements were done for three other formulations to confirm the polymerisation of two systems. The first one was the neat frontal formulation $(F P)$. The others were based on the formulation $F P \_20 H D D A-B C P C$, but without BCPC (FP_20HDDA) and one without HDDA ( $\left.F P \_B C P C\right)$.

The DSC plots of these formulations are shown in Fig. 4. It can be seen that the radical-induced cationic frontal polymerisation of $F P$ rapidly occurs with a high and sharp exothermic peak at the temperature higher than $80{ }^{\circ} \mathrm{C}$. In comparison with $F P$, the presence of BCPC in the formulation $F P \_B C P C$ results in a reaction at lower temperature, which means that the radicals formed from BCPC can undergo a redox reaction with the photoacid generator to liberate a super acid for the cationic ring-opening of the epoxide. The exothermic peak of $F P \_B C P C$ is wider and lower than those of $F P$, which could be since the radicals from BCPC are less effective in the redox reaction with the photoacid generator than those from TPED. This statement was confirmed by

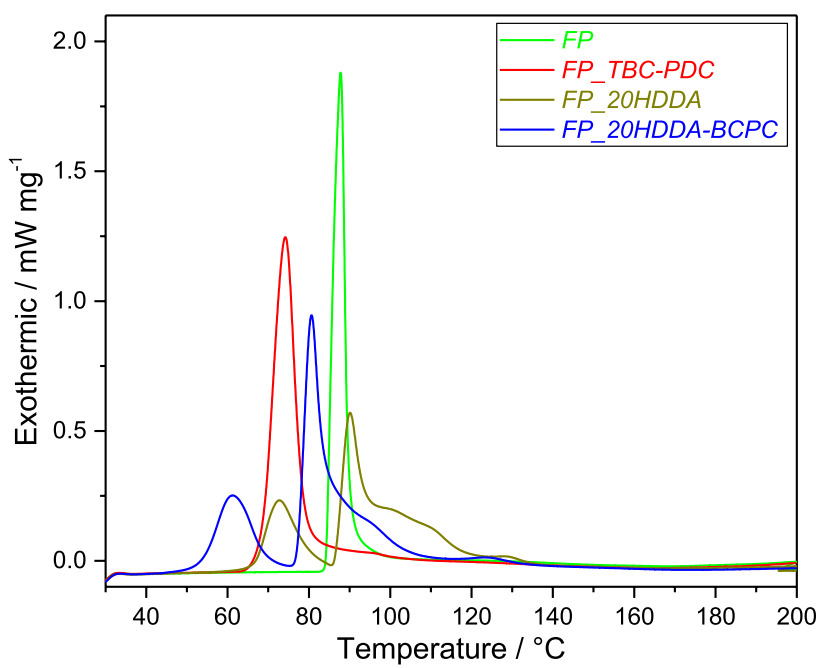

Fig. 4 DSC plots of the formulations $F P, F P \_B C P C, F P \_20 H D D A$ and $F P \_20 H D D A-B C P C$
Fig. 3 Chemical structure of components in the frontal formulation $(F P)$

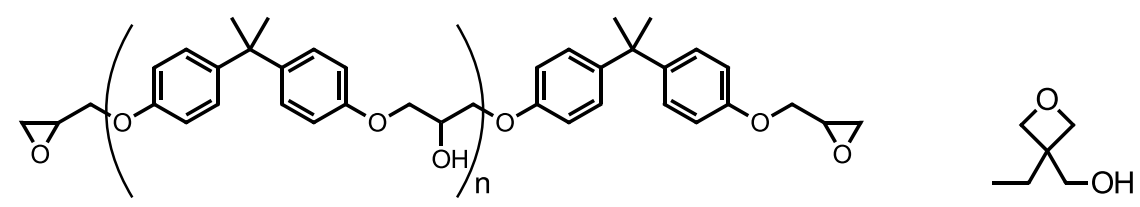

bisphenol-A diglycidyl ether

BADGE
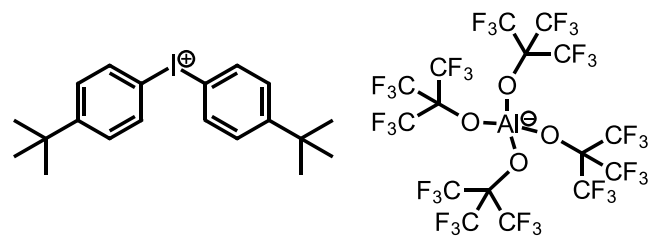

bis(4-tert-butylphenyl)iodonium tetrakis(perfluoro-tert-butyloxy)aluminate

I-Al (3-ethyloxetan-3-yl)methanol EOM

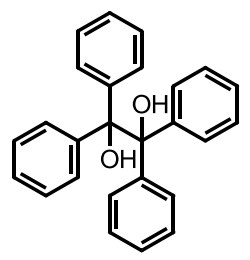

1,1,2,2-tetraphenyl-1,2-ethandiol TPED 
DSC measurements of two frontal formulations containing $2 \mathrm{~mol} \%$ of different radical thermal initiators (TPED and BCPC, Fig. S5, supporting information). With the use of $\mathrm{BCPC}$, even though the cationic ring-opening reaction occurred at lower temperature, the exothermic peak of this formulation is broader and lower than those of the $F P$ with TPED (Fig. S5, Supporting information). In cases of the formulations containing HDDA, there are two separated exothermic peaks during the measurements. The first one is the radical polymerisation of HDDA, while the second is the cationic ring-opening polymerisation. In FP_2OHDDA, the radical polymerisation is observed at around $70{ }^{\circ} \mathrm{C}$, which was initiated by the radicals cleaved from TPED molecules. The polymerisation peak at around $70{ }^{\circ} \mathrm{C}$ of formulation containing only HDDA and TPED as radical thermal initiator is shown in Fig. S6 (Supporting information). In case of $F P \_20 H D D A-B C P C$, the radicals formed from BCPC result in the polymerisation of HDDA at lower temperature. A shoulder at the second peak in these two measurements might be due to effect of polyacrylates on the ring-opening polymerisation of the cationic monomers. The most important information from these measurements is the radical polymerisation and the cationic ring-opening reaction did not take place at the same time. In all the cases, the radical polymerisation always finished before starting the cationic reaction.

To deeply investigate effects of BCPC on the radical polymerisation and cationic ring-opening reaction, real time (RT)-NIR rheology measurements were conducted for these four formulations introduced above. The rheology measurements were conducted at $70{ }^{\circ} \mathrm{C}$ for at least $60 \mathrm{~min}$. During the measurements, NIR spectra were recorded every $3 \mathrm{~min}$ to follow the double bond and epoxy group conversion.

Figure 5 shows the rheology data of the four formulations. It can be seen that the storage and loss moduli of $F P$ containing only the frontal formulation are stable during the whole measurement. This means that the ring-opening reaction of the cationic monomers did not take place during the measurement at $70{ }^{\circ} \mathrm{C}$. With $F P_{-} B C P C$ containing the frontal formulation and $\mathrm{BCPC}$, the storage modulus curve crossovers the loss modulus at a gel time, $t_{\mathrm{gel}}$, of about $30 \mathrm{~min}$. The result indicates that radicals liberating from the decomposition of BCPC interact with the photoacid generator $\mathrm{I}-\mathrm{Al}$ to promote the cationic ring-opening polymerisation. In comparison with $F P \_B C P C$, the formulation containing HDDA ( $F P \_20 H D D A-B C P C$ ) has a shorter gel time of about $16 \mathrm{~min}$, while the maximum storage modulus is lower. This illustrates that the formed radicals selectively attack the double bonds to radically polymerise HDDA and no cationic ring-opening reaction occurs. This assumption can be confirmed by the NIR measurements below. Furthermore, the storage and loss moduli of the formulation FP_2OHDDA without BCPC slowly increase after $80 \mathrm{~min}$,

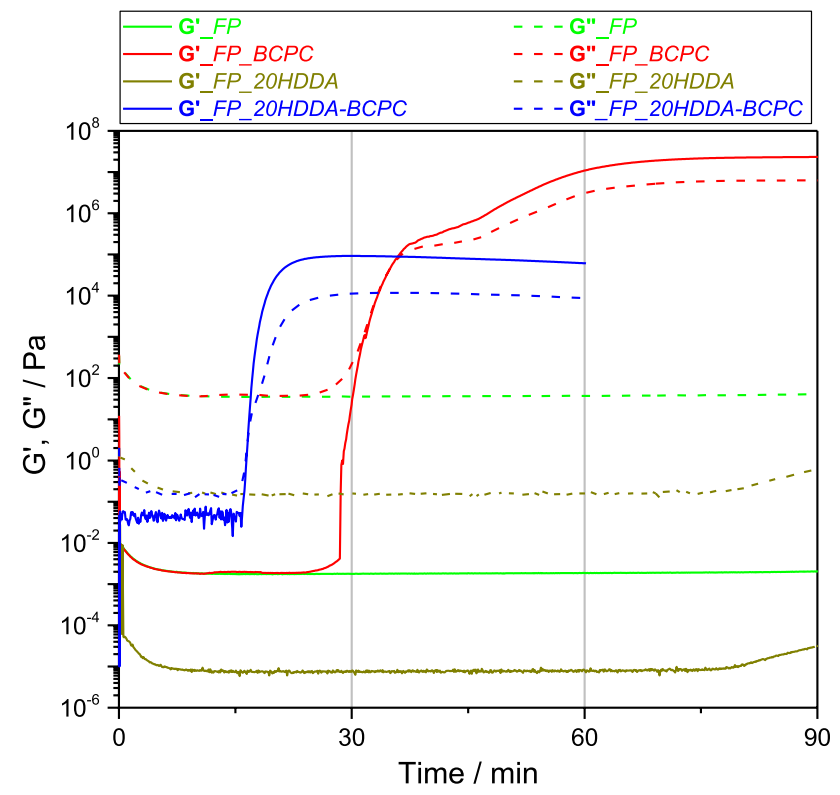

Fig. 5 Rheology measurements at $70{ }^{\circ} \mathrm{C}$ of the formulations $F P, F P$ BCPC, FP_2OHDDA and FP_2OHDDA-BCPC

which attributes to the polymerisation of HDDA caused by the radicals from TPED. This is in an agreement with the DSC study above.

NIR spectra measured after $0,15,30$ and $60 \mathrm{~min}$ at $70{ }^{\circ} \mathrm{C}$ of the formulation containing $20 \mathrm{wt} \%$ HDDA (FP_20HDDA$B C P C$ ) are shown in Fig. S7 (Supporting information). In the NIR spectra, peaks at $4530 \mathrm{~cm}^{-1}$ and $4620 \mathrm{~cm}^{-1}$ are the epoxy and phenyl signals, respectively [43, 44]. The peaks at 4483,4740 and $6160 \mathrm{~cm}^{-1}$ are assigned to the double bonds of HDDA [43, 45, 46]. In addition, a decrease in the intensity of these double bond signals during the radical polymerisation can be seen in Fig. S8 (Supporting information), showing NIR spectra of the formulation containing only HDDA and $2 \mathrm{~mol} \%$ BCPC measured at $50{ }^{\circ} \mathrm{C}$ (around polymerisation temperature in Fig. 2) after 0, 5 and $10 \mathrm{~min}$.

During the RT-NIR rheology measurement, the signals at 4530 and $6160 \mathrm{~cm}^{-1}$ were chosen to follow the epoxy group and double bond conversion, respectively. The conversion was calculated by decrease of the integral of the functional groups referenced to the integral of the phenyl signal at $4620 \mathrm{~cm}^{-1}$ which does not change during the measurement. Owing to the overlap of the double bond signal at $4483 \mathrm{~cm}^{-1}$ and epoxy ring at $4530 \mathrm{~cm}^{-1}$, separation of these peaks was done using a peak deconvolution function in OriginPro 2020 SR1 9.7.0.188. Afterwards, area of the signals at $4530 \mathrm{~cm}^{-1}$ (epoxy ring), $6160 \mathrm{~cm}^{-1}$ (double bond) and $4620 \mathrm{~cm}^{-1}$ (phenyl as a reference) was integrated using the same software to calculate the functional group conversion.

In Fig. 6, the round-marker plots (green and dark yellow) corresponding to the epoxy group conversion stably remain 


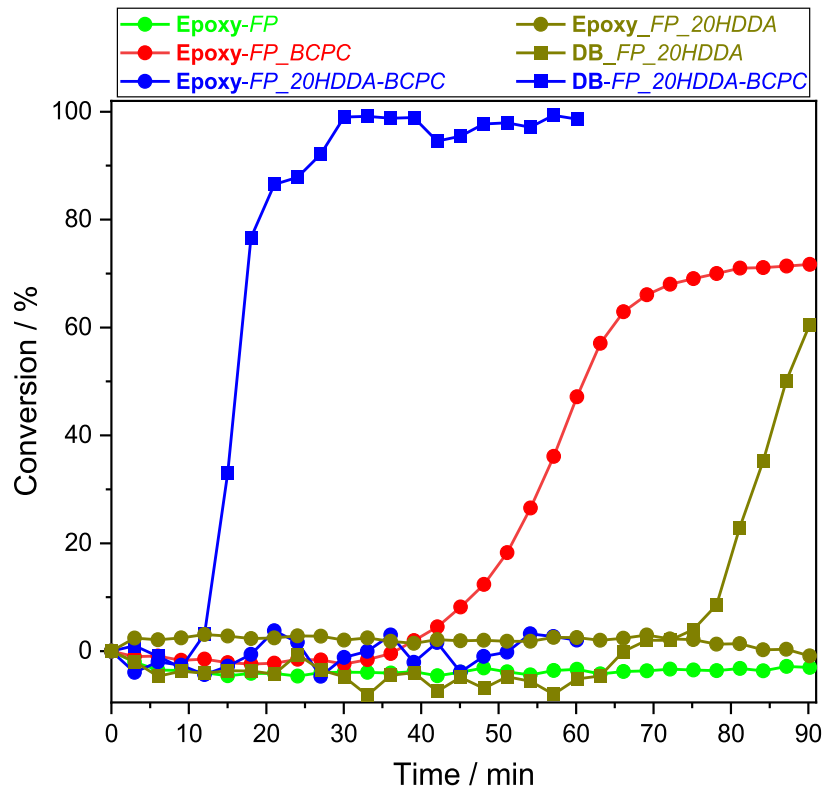

Fig. 6 The epoxy group and double bond conversion of the formulations $F P, F P \_B C P C, F P \_20 H D D A$ and $F P \_20 H D D A-B C P C$

at around zero percent conversion, which indicate that the cationic ring-opening reaction of the epoxides did not occur during the measurement of FP and FP_20HDDA formulations containing no BCPC. In $F P \_B C P C$, the radicals formed from $\mathrm{BCPC}$ interact with the PAG liberating a super acid to start the cationic polymerisation of the epoxides. Here, at $70{ }^{\circ} \mathrm{C}$, the epoxy group conversion starts to increase slowly after $30 \mathrm{~min}$ and reaches about $70 \%$ after $90 \mathrm{~min}$. With the full formulation $F P \_20 H D D A-B C P C$, the radicals from BCPC selectively attack the double bonds with high electron density to start the polymerisation of HDDA, which results in a significant increase in the double bond conversion after $10 \mathrm{~min}$. After $30 \mathrm{~min}$, the double bond conversion reaches values of more than $90 \%$ and nearly full conversion after $60 \mathrm{~min}$. Moreover, the epoxy group conversion of this formulation is $0 \%$ all the time, which means the cationic ring-opening polymerisation did not take places. This confirms that the radicals formed from BCPC prefer attacking the double bonds to undergo the radical polymerisation than reacting with the photoacid generator to form the super acid for the cationic polymerisation.

Therefore, it can be stated that BCPC is the most suitable initiator for this study. The radicals can react with the PAG and therefore start the cationic ring-opening of the epoxides at high temperatures. However, in the presence of radically polymerisable monomers like acrylates, the radicals selectively attack the double bonds and undergo the radical polymerisation. Furthermore, also the radicals formed during the homopolymerisation of HDDA do not decompose the cationic photoinitiator.
Table 1 Summary of the RT-NIR rheology study of formulations containing various amounts of HDDA

\begin{tabular}{llllr}
\hline Formulation & $t_{\mathrm{s}} / \mathrm{min}$ & $t_{\mathrm{gel}} / \mathrm{min}$ & $\mathrm{DBC}_{60} / \%$ & $\mathrm{G}_{60}^{\prime} / \mathrm{Pa}$ \\
\hline$F P \_5 H D D A-$ & $60.2 \pm 0.1-$ & $56.8 \pm 2.9$ & $0.1 \pm 0.0$ \\
$\quad B C P C$ & & & & \\
$F P_{-} 10 H D D A-$ & $24.5 \pm 0.4$ & $32.1 \pm 0.0$ & $98.3 \pm 1.7$ & $1022 \pm 323$ \\
$\quad B C P C$ & & & & \\
$F P \_15 H D D A-$ & $17.5 \pm 0.9$ & $20.8 \pm 0.9$ & $99.0 \pm 0.8$ & $30,750 \pm 8040$ \\
$\quad B C P C$ & & & & \\
FP_20HDDA- & $16.1 \pm 0.6$ & $17.5 \pm 1.3$ & $98.2 \pm 0.2$ & $58,260 \pm 3820$ \\
BCPC & & & & \\
\hline
\end{tabular}

\section{Effects of amount of acrylates on the gelation process}

In this study, formulations for preparation of the gels were prepared with different weight percentages (wt $\%)$ of the acrylate portion. Ratios of the frontal portion $(F P)$ to the acrylate portion (HDDA-BCPC) were 95:5, 90:10, 85:15, $80: 20$ in wt $\%$, respectively. Both components of these formulations contain the given fixed amount of initiators shown in the previous chapter. All the formulations were purged with argon for $5 \mathrm{~min}$ and then immersed in an ultrasound bath (with cool water) for $10 \mathrm{~min}$ to remove dissolved oxygen and bubbles.

First, the RT-NIR rheology measurement was conducted for all the formulations. The rheology data and the conversion of double bonds and epoxy groups for all the formulations are shown in Figs. S9 and S10 (Supporting information). In accordance to the above discussed results, only the radical polymerisation took place during the whole measurements. This can be seen by an increase in the double bond conversion, while the epoxy group conversion is around zero. Table 1 presents a summary of measurements data. In addition to the gel time $\left(t_{\mathrm{gel}}\right), t_{\mathrm{s}}$ is the time when the radical polymerisation starts and the storage modulus starts to increase. $\mathrm{DBC}_{60}$ and $\mathrm{G}_{60}^{\prime}$ are the double bond conversion and the storage modulus at $60 \mathrm{~min}$ of the measurement, respectively.

These results indicate that the formulation containing $5 \mathrm{wt} \%$ HDDA portion has very slow radical polymerisation and does not have a gel point due to the too low amount of acrylates. With an increase of HDDA amount, it is obvious that the gelation time decreases. In addition, time gaps between $t_{\text {gel }}$ and $t_{\mathrm{s}}$ decrease with the increase in HDDA amount, which means that the rate of the radical polymerisation increases. The results also reveal that the double bond conversion at $60 \mathrm{~min}, \mathrm{DBC}_{60}$, is close to $100 \%$ in the formulations consisting of $10 \mathrm{wt} \%$ HDDA or higher. Furthermore, the storage modulus value at the end of the measurement gives information about stiffness of the gels. In Table $1, \mathrm{G}_{60}^{\prime}$ of the formulation FP_5HDDA-BCPC is 
very low and the specimen was still liquid. This value is around $1000 \mathrm{~Pa}$ for the formulation FP_10HDDA-BCPC which results in a flexible gel. The flexibility of this gel can be seen in Fig. S11 and Video 1 (Supporting information), where it was used to make a "bretzel" form cured by RICFP. With an increase of HDDA amount, the storage modulus value at 60 min significantly increases, which is owned to an increase of crosslink density. With $20 \mathrm{wt} \%$ of HDDA portion, $\mathrm{G}_{60}^{\prime}$ of the gel is about 50 times higher than the value of FP_10HDDA-BCPC. Owing to the increase in the gel stiffness to impractical heights, formulations containing more than $20 \mathrm{wt} \%$ HDDA were not being considered.

Additional to the RT-NIR measurement, all the formulations were transferred to $1 \mathrm{~cm}^{3}$ syringes. Then, the gelation process or the radical polymerisation of HDDA was done by immersing the syringes in a water bath at $60{ }^{\circ} \mathrm{C}$ for $90 \mathrm{~min}$. In this experiment, the temperature for the radical polymerisation was set to $60{ }^{\circ} \mathrm{C}$ instead of $70{ }^{\circ} \mathrm{C}$ in the RTNIR rheology measurement to prevent localised over heating which might lead to the frontal polymerisation of the cationic monomers. The gels were then collected and the NIR spectra were measured to check the double bond conversion (DBC). Gel content was also determined by extracting the specimen with dichloromethane.

Table 2 illustrates the gel content and double bond conversion of the four specimens. It can be seen that double bond conversion for all the specimens is very similar to those obtained from the rheology measurements at $70^{\circ} \mathrm{C}$. The gel content of the specimens FP_10HDDA-BCPC, $F P \_15 H D D A-B C P C$ and $F P \_20 H D D A-B C P C$ are very close to the initial weight percentages of the acrylate portion. Furthermore, HPLC measurements of dried residues from the extracted solutions were done. The chromatogram of FP_10HDDA-BCPC in Fig. S12 (Supporting information) shows no HDDA signal at retention time of about $8 \mathrm{~min}$. This strengthens the statement that a high double bond conversion was obtained and the cationic polymerisation of the epoxy system did not take place during the gelation process. In case of the specimen $F P \_5 H D D A-B C P C$, the gel content is lower than the initial weight percentage of HDDA portion, which is due to low double bond conversion.

Table 2 Gel content and double bond conversion of the specimens from formulations containing various amounts of HDDA

\begin{tabular}{lllr}
\hline Gel & $\begin{array}{l}\text { HDDA:FP } \\
\text { wt\%:wt } \%\end{array}$ & DBC/\% & Gel content/\% \\
\hline$F P \_5 H D D A-B C P C$ & $05: 95$ & $67.7 \pm 7.2$ & $1.50 \pm 0.34$ \\
$F P \_10 H D D A-B C P C$ & $10: 90$ & $97.0 \pm 0.0$ & $9.92 \pm 0.17$ \\
$F P \_15 H D D A-B C P C$ & $15: 85$ & $97.2 \pm 0.5$ & $15.21 \pm 0.37$ \\
$F P \_20 H D D A-B C P C$ & $20: 80$ & $98.3 \pm 1.1$ & $21.05 \pm 0.29$ \\
\hline
\end{tabular}

Furthermore, the specimens (except $F P \_5 H D D A-B C P C$ ) remained after the extraction with similar shapes, but in smaller sizes. This reveals that a homogeneous network of polyacrylates was formed in these gels and was not collapsed during the extraction with the solvent. Moreover, the gel containing $10 \mathrm{wt} \%$ acrylate (FP_10HDDA-BCPC) was chosen to observe the extraction process under a light microscope. A thin section of about $0.5 \mathrm{~mm}$ thickness was put on a small petri dish which was placed under the light microscope attached with a camera. Figure 7 illustrates light microscopic images of the gel. The top and middle images are the gel before immersing in dichloromethane, which indicate a bubble-free surface. The bottom image was taken at $4 \mathrm{~min}$ after adding the solvent, a flow of bubbles was formed in the gel due to diffusion of dichloromethane and the extraction process. First, the solvent diffused into the section and
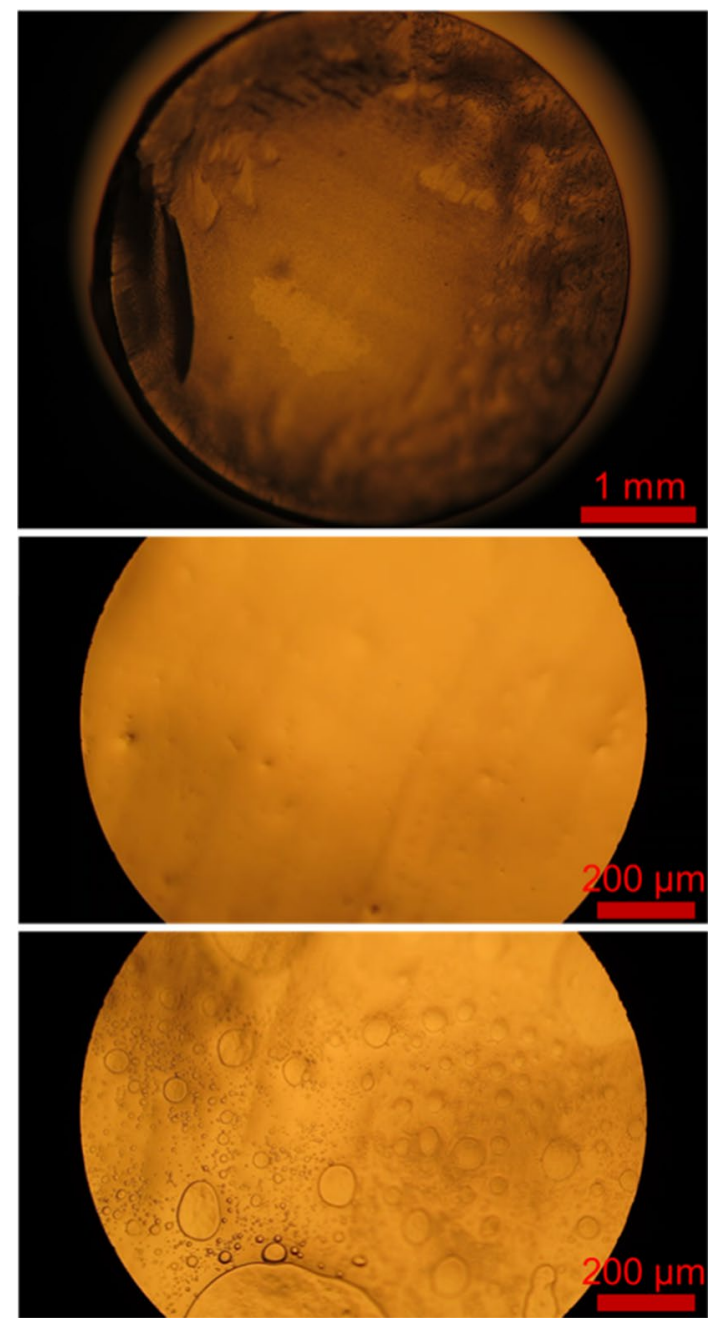

Fig. 7 Light microscopy images of the gel FP_10HDDA-BCPC (top: before adding $\mathrm{CH}_{2} \mathrm{Cl}_{2}, 5$ times of magnification; middle: before adding $\mathrm{CH}_{2} \mathrm{Cl}_{2}, 20$ times of magnification; bottom: 4 min after adding $\mathrm{CH}_{2} \mathrm{Cl}_{2}, 20$ times of magnification) 
formed many small bubbles on the whole surface. Then, the extraction occurred and the small bubbles combined to form the bigger bubbles.

Figure 8 shows light microscopic images of the extracted specimen (FP_10HDDA-BCPC) after the removal of solvent from the gel content experiment. The top image (taken at $0 \mathrm{~s}$ ) is the extracted gel after dried in a vacuum oven. It can be seen that the diameter of the specimen is about 3 times smaller than the original gel (Fig. 7, top). To observe swelling process, dichloromethane was added on the specimen. The middle image was taken at $30 \mathrm{~s}$ after the addition of the solvent. Owing to the diffusion of the solvent, the specimen was swollen and bubbles were formed. Then, the last image was taken at $40 \mathrm{~s}$ after the middle image when almost all of the solvent evaporated. It is clearly seen in the bottom image that the bubbles almost disappeared and the specimen returned to the original shape as similar in the top
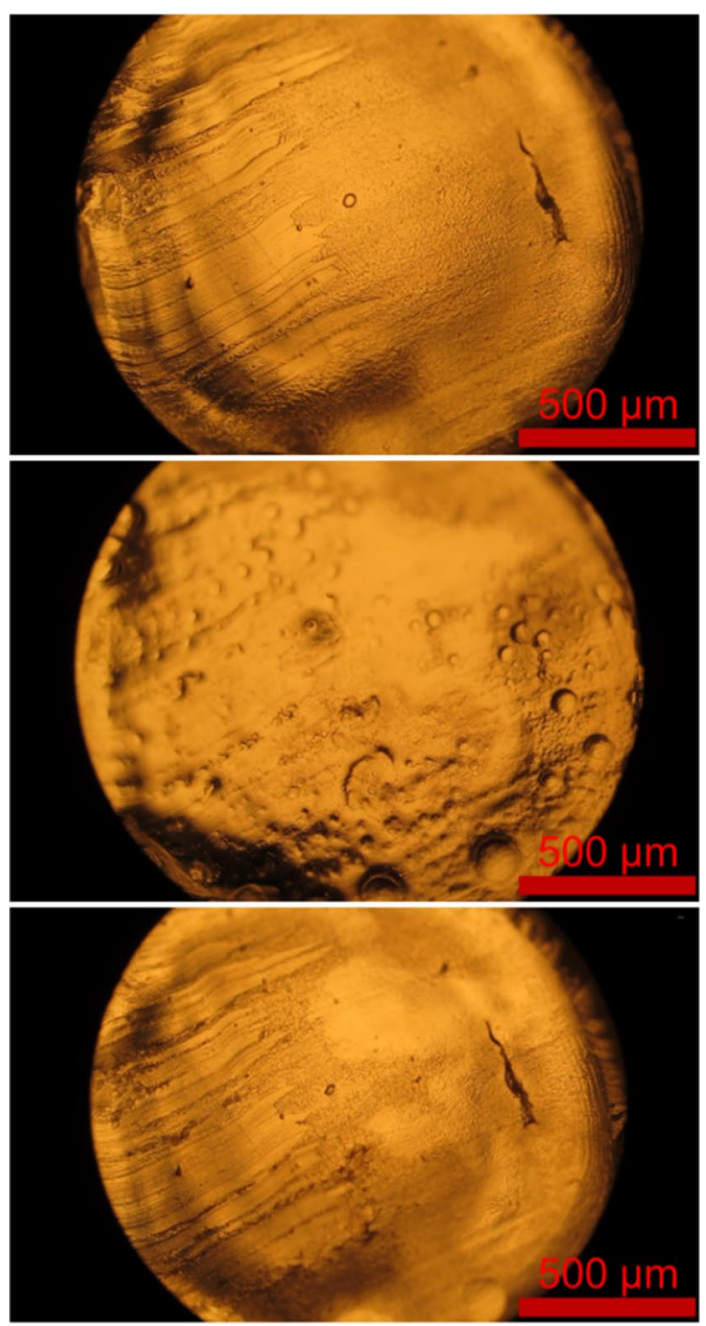

Fig. 8 Light microscopy images of FP_10HDDA-BCPC after extracted with $\mathrm{CH}_{2} \mathrm{Cl}_{2}$ (top: before adding $\mathrm{CH}_{2} \mathrm{Cl}_{2}$, middle: $30 \mathrm{~s}$ in $\mathrm{CH}_{2} \mathrm{Cl}_{2}$, bottom: when $\mathrm{CH}_{2} \mathrm{Cl}_{2}$ evaporated) image. This confirms a homogenous and stable network of polyacrylates in the gel.

\section{Storage stability of the formulation and the gel}

Stability of the formulation decides a processing time window when the impregnation of the fibres should be carried out before the viscosity of the formulation starts to increase. To test the stability, about $3 \mathrm{~g}$ of the formulations were stored at room temperature after the preparation. Following storage time up to 7 days, viscosity and NIR spectra of the formulations were measured at $25^{\circ} \mathrm{C}$. The double bond and epoxy group conversion were calculated from the signal integration in NIR spectra to follow the polymerisation of the monomers.

Figure 9 shows the viscosity and functional group conversion of the formulations containing $10 \mathrm{wt} \%$ and $20 \mathrm{wt} \%$ HDDA portion. It can be seen that the viscosity, double bond and epoxy group conversion of the two formulations have no significant change. This means that the formulations are stable at room temperature up to 7 days, which is long enough for processing. Furthermore, the RT-NIR rheology measurement at $70{ }^{\circ} \mathrm{C}$ was performed for the formulations on day 7 th to check the gelation process. The results are shown in Table S4 (Supporting information). The $t_{\mathrm{s}}, t_{\mathrm{gel}}$ and $\mathrm{DBC}_{60}$ of the formulations on day 7 th are close to these values of the fresh formulations.

In addition, storage stability of the gel is an important parameter in the study of prepregs. It decides the time the

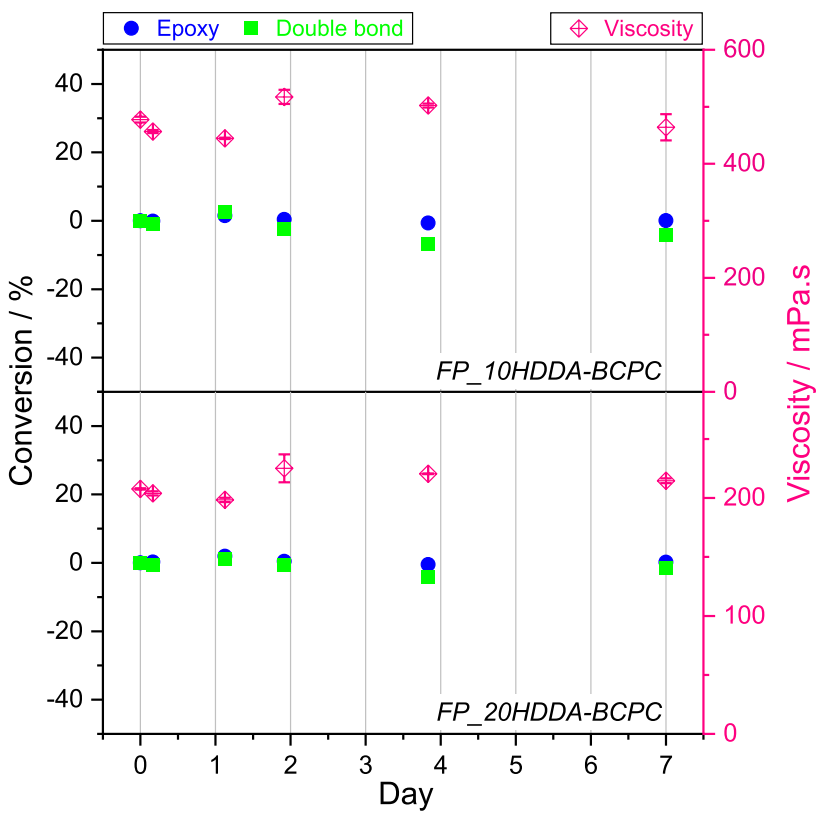

Fig. 9 Viscosity, double bond and epoxy group conversion of the formulations $F P_{-} 10 H D D A-B C P C$ (upper) and $F P \_20 H D D A-B C P C$ (lower) up to the storage of 7 days at room temperature 


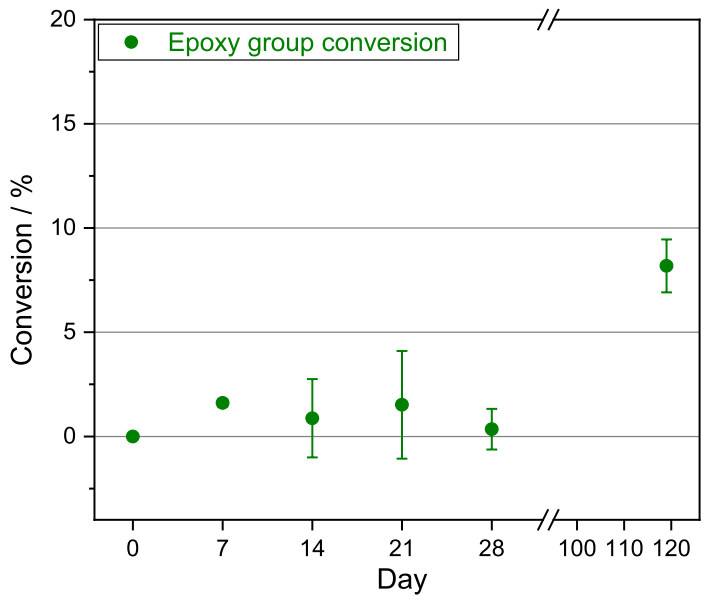

Fig. 10 Epoxy group conversion of the gel FP_10HDDA-BCPC measured on different days during storage

prepreg can be stored before usage. For the test, the gel consisting of $10 \mathrm{wt} \%$ HDDA was collected in a brown vial and kept in an oven at $50{ }^{\circ} \mathrm{C}$. Following a time schedule, a small piece of the gel was taken and measured the IR spectrum. The epoxy group conversion was calculated using the usual method to check the stability of the gel.

Figure 10 illustrates that the epoxy group conversion remains stable at around $0 \%$ up to 1 month. Then, this value slightly increases to about $8 \%$ after about 4 months at $50{ }^{\circ} \mathrm{C}$. After 1 and 4 months, the gels were polymerised by RICFP. The frontal velocity and frontal temperature of these experiments are shown in Table S5 (Supporting information). Even after 4 months, a fast and stable front was still observed with a velocity of $4.9 \mathrm{~cm} \mathrm{~min}^{-1}$ as compared to $6.3 \mathrm{~cm} \mathrm{~min}^{-1}$ in RICFP of the fresh gel, while the frontal temperatures were similar.

\section{Radical-induced cationic frontal polymerisation of the gel}

In this study, all the gels which were removed from the syringes, were placed on a PTFE mold. The gel was then polymerised by RICFP. The initiation of RICFP was done on one end of the mold with UV/Vis-light of 320 to $500 \mathrm{~nm}$ and a light intensity of $3 \mathrm{~W} \mathrm{~cm}^{-2}$ at the tip of the light guide (about $500 \mathrm{~mW} \mathrm{~cm}{ }^{-2}$ on surface of the specimen). After initiation, the reaction propagated without further irradiation being necessary.

For comparison, the two formulations $F P$ and $F P \_B C P C$ were treated in the water bath at $60^{\circ} \mathrm{C}$ for $90 \mathrm{~min}$, to mimic the gelation process. $F P$ is the frontal formulation, while the composition of $F P_{-} B C P C$ is the same as the formulation $F P \_20 H D D A-B C P C$ but without HDDA. After treatment, the formulations were filled in a PTFE mold and polymerised by RICFP with the same initiation and setup as above.
The frontal parameters and epoxy group conversion for all specimens are shown in Table 3. It can be seen that the epoxy group conversion is always higher than $98 \%$ for all the specimens. This means that the presence of polyacrylates has no significant effect on the curing degree of the cationic monomers. The frontal velocity and frontal temperature of the $F P$ formulation are about $14 \mathrm{~cm} \mathrm{~min}^{-1}$ and $260{ }^{\circ} \mathrm{C}$, respectively. These values are slightly higher in the FP_BCPC specimen. This is due to the presence of the additional amount of BCPC. With the specimens containing acrylates, the frontal parameters decrease while the amount of HDDA increases. On the one hand, after the treatment of the formulations at $60{ }^{\circ} \mathrm{C}$, the polyacrylate was formed and dispersed in the gels. The polyacrylate plays a role as a filler. Owing to the heat uptake, while the filler content increases, the frontal velocity and the frontal temperature decrease. On the other hand, the decrease of the cationic monomer fraction results in a reduction of the frontal parameters. The similar behaviour was discussed in our previous work about particle filled epoxy composites [28].

\section{Effects of gelation process on thermal mechanical properties of the final polymers}

DMTA measurement of the RICFP specimens was performed in a temperature range of $-50{ }^{\circ} \mathrm{C}$ to $200{ }^{\circ} \mathrm{C}$ with two heating runs. The storage modulus and loss tangent of all the specimens obtained from the first heating run are shown in Fig. 11.

Specimen $F P$ has only a $T_{\mathrm{g}}$ peak at around $132^{\circ} \mathrm{C}$. Additional to the $T_{\mathrm{g}}$ at the similar temperature, the specimen $F P \_B C P C$ which contains an added amount of the initiator BCPC, has a second $T_{\mathrm{g}}$ peak at around $-15^{\circ} \mathrm{C}$. The appearance of the second $T_{\mathrm{g}}$ peak might be due to an inhomogeneous polymer network which caused by a slightly lower epoxy group conversion of this specimen and the thermal treatment process of the formulation. As discussed in the previous chapter, during treatment of the formulation at $60{ }^{\circ} \mathrm{C}$ the radicals formed from BCPC interact with the photoacid generator liberating a super acid and starting the cationic

Table 3 Frontal parameters and epoxy group conversion for all specimens

\begin{tabular}{lcll}
\hline Specimen & $V_{\mathrm{F}} / \mathrm{cm} \mathrm{min}^{-1}$ & $T_{\mathrm{F}} /{ }^{\circ} \mathrm{C}$ & $\begin{array}{l}\text { Epoxy group } \\
\text { conversion } / \%\end{array}$ \\
\hline$F P$ & $14.2 \pm 0.1$ & $260 \pm 11$ & $99.2 \pm 1.9$ \\
$F P \_B C P C$ & $16.6 \pm 0.0$ & $265 \pm 6$ & $98.6 \pm 3.8$ \\
$F P \_5 H D D A-B C P C$ & $8.1 \pm 0.2$ & $241 \pm 7$ & $99.4 \pm 5.0$ \\
$F P \_10 H D D A-B C P C$ & $6.3 \pm 0.6$ & $220 \pm 2$ & $99.5 \pm 2.2$ \\
$F P \_15 H D D A-B C P C$ & $4.8 \pm 0.1$ & $219 \pm 4$ & $99.5 \pm 4.3$ \\
$F P \_20 H D D A-B C P C$ & $3.2 \pm 0.1$ & $195 \pm 5$ & $99.5 \pm 2.7$
\end{tabular}




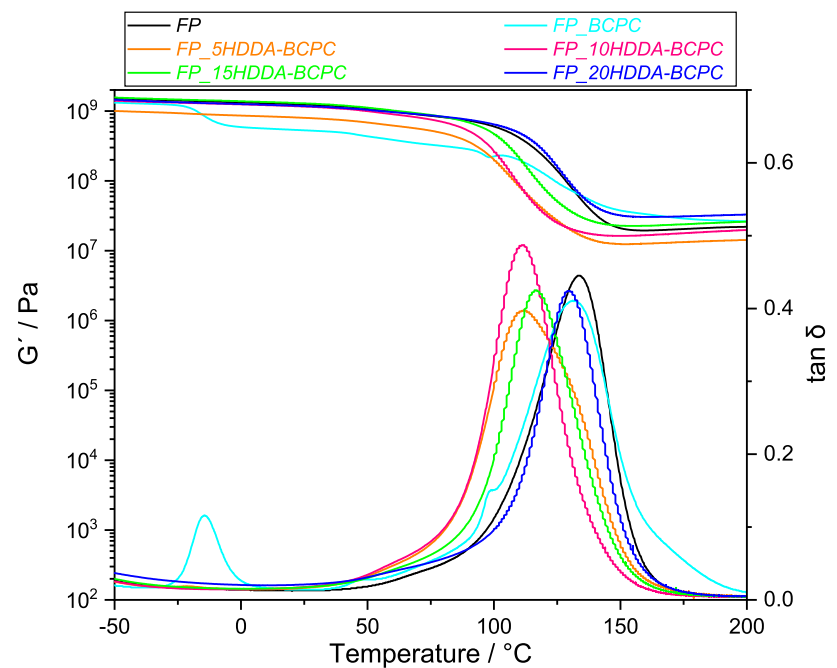

Fig. 11 Storage modulus and $\tan \delta$ versus temperature obtained from the first heating run

ring-opening of the epoxy monomers. This rather sluggish initiation process might result in formation of oligomers. Even though the frontal polymerisation occurred at high temperature, this very fast curing process might not give enough time for the oligomers to arrange and bond to propagating polymer chains. The oligomers might also affect the epoxy group conversion of this specimen which was slightly lower than other specimens.

In addition, the specimen containing $5 \mathrm{wt} \%$ HDDA portion $\left(F P \_5 H D D A-B C P C\right)$ has a broad $T_{\mathrm{g}}$ peak which results from an inhomogeneous network of acrylate and epoxy. The low HDDA amount is not enough to form a stable gel in this specimen. In the liquid state, a phase separation of polyacrylate from the epoxy components occurred easily, which results in the inhomogeneous network in the final polymer. With the higher amount of the HDDA, the polymer network becomes more homogeneous which can be seen at the sharp and narrow $T_{\mathrm{g}}$ peaks. In these specimens, a homogeneous dispersion of the polyacrylates in the cationic monomers was confirmed in the gel content experiment and the light microscopic images. The network remains stable in the final polymers.

Figure 12 illustrates the second heating data of the DMTA measurement for all the specimens. It can be seen that in the specimen $F P \_B C P C$ the $T_{\mathrm{g}}$ peak at low temperature disappeared and only one broad $T_{\mathrm{g}}$ peak is observed. This is due to reorganisation of the inhomogeneous network combining with a post curing in the first heating run at high temperatures. These arrangement and post curing also occurred in the other specimens, which leads to the narrower $T_{\mathrm{g}}$ peaks. The change is most obvious in the specimen FP_5HDDA$B C P C$, which is clearly seen in a decrease of full width at half maximum of the $\tan \delta$ peak from 46 to $34^{\circ} \mathrm{C}$ (Table S6,

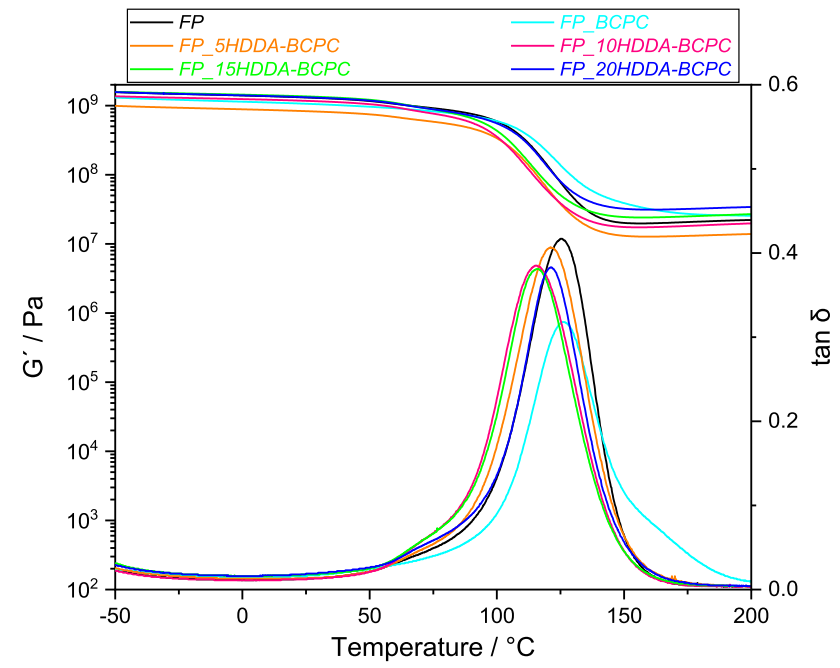

Fig. 12 Storage modulus and $\tan \delta$ versus temperature obtained from the second heating run

Supporting information). In addition, the glass transition temperature slightly decreases with an increase of HDDA amounts from 0 to $15 \mathrm{wt} \%$ which correspond to the specimens FP, FP_5HDDA-BCPC, FP_10HDDA-BCPC and $F P \_15 H D D A-B C P C$, respectively. This results from the decrease of epoxy fraction. Afterwards, with $20 \mathrm{wt} \%$ HDDA ( $\left.F P \_20 H D D A-B C P C\right)$ the $T_{\mathrm{g}}$ increases again to a similar value of $F P \_5 H D D A-B C P C$, which is due to an increase of crosslinking density contributed by polyacrylates.

\section{Preparation of RICFP-prepreg and its composites}

In this study, the formulation consisting of $10 \mathrm{wt} \%$ HDDA portion and $90 \mathrm{wt} \%$ frontal portion (FP_10HDDA-BCPC) was chosen to impregnate carbon fibres. The RICFPprepregs with different fibre contents were produced and then polymerised by RICFP as described in the experimental section.

Figure 13 shows the frontal velocity and frontal temperature of the prepreg specimens. It can be seen that the frontal temperature for all the specimens is similar, while the frontal velocity is slightly faster in the case of composites. Normally, the frontal velocity decreases with an increase of filler content, which was discussed in the previous works [28]. However, if the specimens contain thermally conductive elements and they align along the propagated path of the front, the frontal velocity could be faster than those of the matrix $[47,48]$. This is also applicable in this experiment where the thermally conductive carbon fibre tow results in the faster frontal velocity. With the fibre content higher than $40 \mathrm{wt} \%$, the prepreg was collapsed during the removal out of the glass tube. This might be due to the amount of the 


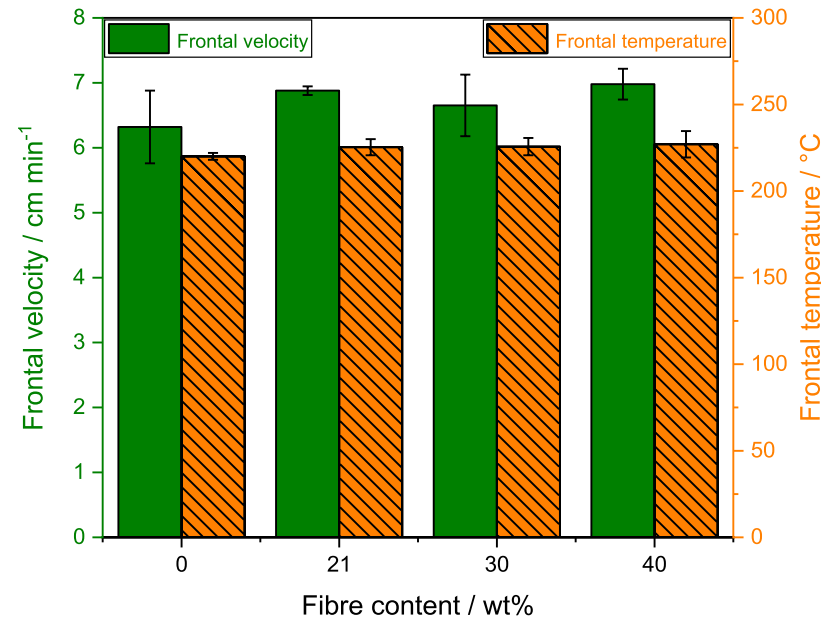

Fig. 13 Frontal parameters of the prepregs with different fibre contents

liquid formulation, which was not enough to form a stable gel network and to hold the fibres together.

For proof of concept, a snowflake composite was prepared by assembling RICFP-prepreg segments. Owing to sticky surface of the prepregs, the snowflake form remained stable with 16 connecting points. The snowflake was successfully polymerised by RICFP, which can be seen in Fig. 14 and Video 2 (Supporting Information).

\section{Conclusion}

In this study, the radical polymerisation of 1,6-hexanediol diacrylate (HDDA) in presence of the frontally polymerisable components was investigated to form the B-stage for preparation of RICFP-prepreg. The study revealed that bis(tert-butylcyclohexyl)peroxydicarbonate (BCPC) was the most suitable radical thermal initiator which resulted in a fast polymerisation even at temperatures below $70{ }^{\circ} \mathrm{C}$. Furthermore, in a formulation consisting of acrylates and epoxy monomers, radicals cleaved from BCPC selectively attacked the double bonds for the radical polymerisation and had no effect on the cationic ring-opening reaction. The study also indicated that with increase of HDDA amount the radical polymerisation was faster, while RICFP of the gels had lower frontal temperature and frontal velocity. Due to an increase in crosslink density, the higher HDDA amount led to a stiffer gel. With $10 \mathrm{wt} \%$ HDDAbased formulation, the resultant gel was sticky, bubblefree, flexible and especially had good storage stability. After 4 months at $50{ }^{\circ} \mathrm{C}$, the epoxy group conversion just increased to $8 \%$ and a stable front was still obtained. The RICFP-prepreg was prepared with different weight percentages of carbon fibre tow. With up to $40 \mathrm{wt} \%$ fibres, RICFP was still possible and even faster frontal velocity than those of the matrix gel were obtained. The successful production of a snowflake composite was a first proof for the use of the RICFP-prepreg.

\section{Experimental}

Bisphenol-A diglycidylether (BADGE, Araldite MY 7901, Huntsman), (3-ethyloxetan-3-yl)methanol (EOM, Doublemer 401, Double Bond Chemical), 1,1,2,2-tetraphenylethane-1,2-diol (TPED, Fluka), bis(4-tert-butylphenyl)iodonium tetrakis(perfluoro-tert-butyloxy)aluminate (I-Al, Synthon), $\alpha, \alpha^{\prime}$-azoisobutylronitrile (AIBN, Sigma-Aldrich), 4,4'-azobis(4-cyanovaleric acid) (ACVA, Sigma-Aldrich), potassium peroxodisulfate (KPS, Sigmal-Aldrich), bis(tertbutylcyclohexyl)peroxydicarbonate (BCPC, Sigma-Aldrich), ditetradecyl peroxydicarbonate (PODIC, Pergan), 1,6-hexanediol diacrylate (HDDA, abcr), carbon fibre tow (Toolcraft Conrad Electronic SE) were used as received.
Fig. 14 The resultant snowflake composite cured by RICFP (left: digital image; right: IR image)
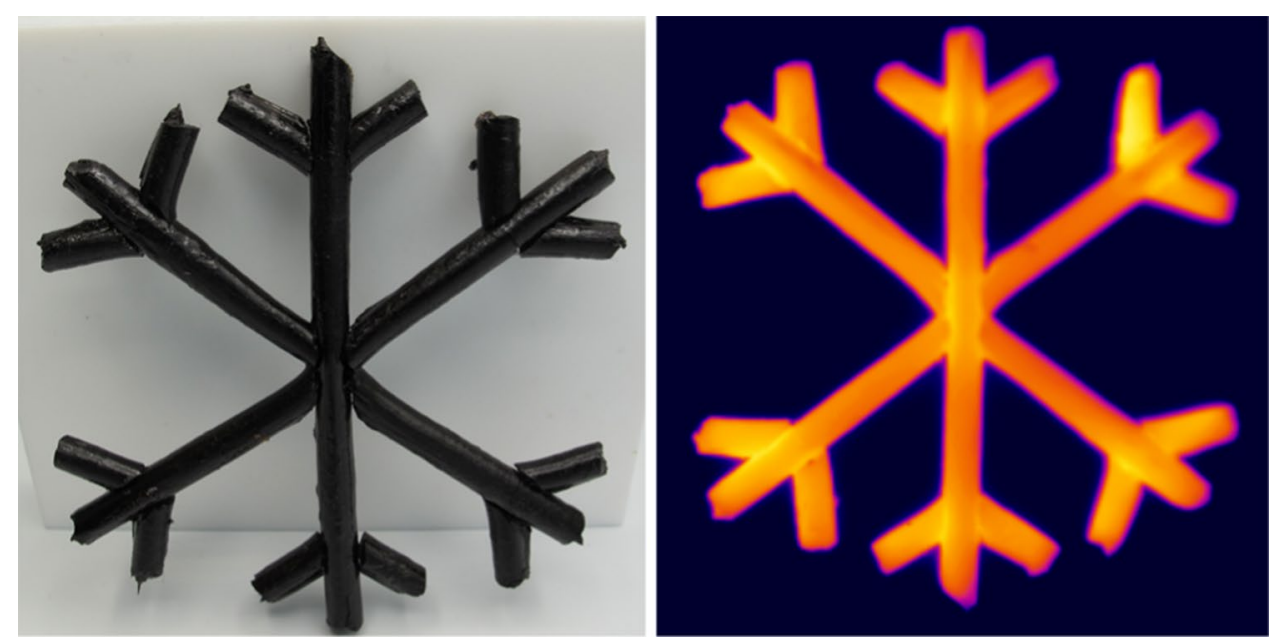


\section{Preparation of formulations, gels and RICFP polymers}

Radically polymerisable formulations were prepared with 1,6-hexanediol diacrylate and $2 \mathrm{~mol} \%$ of different radical thermal initiators, called HDDA-AIBN, HDDA-ACVA, HDDA-BCPC, HDDA-PODIC and HDDA-KPS (Table S1, Supporting information). The formulations were homogenised using a vortex mixer for about $5 \mathrm{~min}$.

A frontal formulation (called $F P$ ) was prepared with BADGE and EOM (with a molar ratio of 100:40, respectively), $2 \mathrm{~mol} \%$ TPED as radical thermal initiator and $1 \mathrm{~mol} \% \mathrm{I}-\mathrm{Al}$ as photoacid generator. The formulation was homogeneously mixed in a speed mixer (DAC 600.2 VAC-P, FlackTek Inc; 2350 rpm, 9 min).

Formulations for preparation of the gel were prepared as mixtures of $H D D A-B C P C$ and $F P$ with different ratios of 5:95, 10:90, 15:85 and 20:80 in wt \%, respectively (Table S2, Supporting information). Then, the formulation was homogenised using the vortex mixer for $1 \mathrm{~min}$. Afterwards, the formulation was purged with argon for $5 \mathrm{~min}$ and then treated in an ultrasound bath (with cool water) for $10 \mathrm{~min}$ to remove dissolved oxygen and bubbles. The obtained formulation was then transferred into a $1 \mathrm{~cm}^{3}$ syringe and radically polymerised or gelled in a water bath at $60{ }^{\circ} \mathrm{C}$, for $90 \mathrm{~min}$ (Fig. S1, Supporting information).

For comparison, two formulations were also treated with the same gelation condition, at $60{ }^{\circ} \mathrm{C}$ for $90 \mathrm{~min}$. The first formulation is the frontal formulation $(F P)$, while the second is a mixture of the frontal formulation and $0.88 \mathrm{wt} \%$ of BCPC. The value of $0.88 \mathrm{wt} \%$ is the weight percentage of BCPC compared to the weight of the frontal formulation portion in the formulation FP_20HDDA-BCPC (Table S2, Supporting information).

The treated formulations and the gels were then filled in a PTFE mold $\left(5 \times 5 \times 70 \mathrm{~mm}^{3}\right)$ and polymerised by RICFP [32]. To follow the front position, a ruler was placed on the mold, along the specimen. During the reaction, a video was recorded using a camera and frontal temperatures were measured using an infrared camera (Optris Xi400). The initiation of RICFP was done on one end of the mold with UV/ Vis-light of 320-500 $\mathrm{nm}$ and a light intensity of $3 \mathrm{~W} \mathrm{~cm}^{-2}$ at the tip of the light guide (about $500 \mathrm{~mW} \mathrm{~cm}^{-2}$ on surface of the specimen). After the initiation, the reaction propagated without further irradiation being necessary. The epoxy group conversion of the RICFP was determined by FT-MIR method which was discribed in our previous works [28, 33].

\section{Differential scanning calorimetry measurement (DSC)}

DSC measurement was conducted for the formulations consisting of HDDA and 2 mol\% of different radical thermal initiators (AIBN, ACVA, BCPC, PODIC, KPS). $15 \mathrm{mg}$ of each formulation were exactly weighed in an aluminium pan, which was subsequently sealed with an aluminium lid. An empty pan was used as reference for all measurements in this study. The pans were placed in a simultaneous thermal analyser (STA 449 F1 Jupiter, NETZSCH) and the temperature was risen from 25 to $200{ }^{\circ} \mathrm{C}$ with a heating rate of $5{ }^{\circ} \mathrm{C} \mathrm{min}{ }^{-1}$. For analysis of the DSC plots, the onset of the exothermal peak was evaluated by laying tangents and intersecting them. Heat of the reaction was determined through the integration of heat flow over the exothermal peak.

To observe the radical polymerisation and cationic ringopening reaction in one measurement, the DSC measurement was performed for the four formulations $F P, F P \_B C P C$, $F P \_20 H D D A$ and $F P \_20 H D D A-B C P C$. The measurement was done with the same above procedure, but with a lower heating rate of $1{ }^{\circ} \mathrm{C} \mathrm{min}-1$.

\section{Real time (RT)-NIR rheology measurement}

To follow the gelation process of the formulation, RT-NIR rheology measurement was performed [43]. The measurements were done on a rheometer Anton Paar MCR302 WESP coupled with Bruker Vertex 80 FT-IR spectrometer. The rheometer was equipped with a parallel plate steel measuring system PP25 (plate diameter of $25 \mathrm{~mm}$ ). Bottom plate of the rheometer was made by an optical glass which allows IR beam goes through. For protection of the glass plate, adhesive polyethylene tape (4668 MDPE, TESA) was used. A sample volume of $150 \mathrm{~mm}^{3}$ was added on the center of the bottom glass plate, on the polyethylene tape. The rheology measurements were performed at $70{ }^{\circ} \mathrm{C}$ and a sample thickness (or gap size) of $200 \mu \mathrm{m}$. The formulation was sheared with a frequency of $1 \mathrm{~Hz}$ and a strain of $1 \%$ for at least $60 \mathrm{~min}$. During the measurements, storage and loss moduli of the specimen were followed. There are some important values for observation of the radical polymerisation and properties of the gel. A point where the storage modulus starts to increase, $t_{\mathrm{s}}(\mathrm{min})$, which relates to the start of the radical polymerisation of HDDA. A point where the storage modulus crossovers the loss modulus, is defined as gel time, $t_{\text {gel }}(\mathrm{min})$. In addition, the storage modulus value at $60 \mathrm{~min}$ of the specimen was collected to compare stiffness of the gels.

During the rheology measurement, the NIR spectra were also measured using a Bruker Vertex 80 FT-IR spectrometer with $\mathrm{CaF}_{2}$ window. Every 3 min, a NIR spectrum was recorded in a wave number range of $4000-7000 \mathrm{~cm}^{-1}$ and a resolution of $8 \mathrm{~cm}^{-1}$. In NIR spectra, peaks at 4530 and $4620 \mathrm{~cm}^{-1}$ are the epoxy and phenyl signals $[43,44]$. The peaks at 4483,4740 and $6160 \mathrm{~cm}^{-1}$ are assigned to the double bonds of HDDA [43, 45, 46]. Double bond and epoxy group conversion were calculated using the phenyl signal as a reference by equations below: 
Epoxy group conversion (EGC), $\%=\left(1-\frac{\frac{A_{4530, t}}{A_{4620, t}}}{\frac{A_{4530,0}}{A_{4620,0}}}\right) \times 100 \%$

Double bond conversion (DBC), $\%=\left(1-\frac{\frac{A_{6160, t}}{A_{4620, t}}}{\frac{A_{6160,0}}{A_{4620,0}}}\right) \times 100 \%$

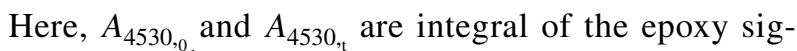
nal $\left(4530 \mathrm{~cm}^{-1}\right)$ at 0 and $t$ min of the measuring time, respectively. $A_{4620,0}$ and $A_{4620,}$ are integral of the reference $\left(4620 \mathrm{~cm}^{-1}\right)$ at 0 and $t \mathrm{~min}$ of the measuring time, respectively. $A_{6160,0}$ and $A_{6160, \mathrm{t}}$ are integral of the double bond signal $\left(6160 \mathrm{~cm}^{-1}\right)$ at 0 and $t$ min of the measuring time, respectively.

Due to the overlap of the epoxy $\left(4530 \mathrm{~cm}^{-1}\right)$ and the double bond signal $\left(4483 \mathrm{~cm}^{-1}\right)$, separation of these signals was done using a peak deconvolution function in OriginPro 2020 SR 1 9.7.0.188. After the deconvolution was done, the signal area of the peaks $\left(4530,4620\right.$ and $\left.6160 \mathrm{~cm}^{-1}\right)$ were integrated to calculate the above conversion. A procedure of the peak deconvolution was described in the supporting information.

\section{Determination of gel content and light microscope images}

Gel content of the specimens (FP_5HDDA-BCPC, $F P_{-} 10 H D D A-B C P C, \quad F P_{-} 15 H D D A-B C P C$ and $F P \_20 H D D A-B C P C$ ) was determined using dichloromethane as a solvent for extraction. A thin section of approximate $1 \mathrm{~mm}$ thickness and $4.8 \mathrm{~mm}$ diameter (about $20 \mathrm{mg}$ ) was immersed in $0.5 \mathrm{~cm}^{3}$ dichloromethane in a $2 \mathrm{~cm}^{3}$ brown vial. Every $1 \mathrm{~h}$ the old solvent was collected and replaced by the same new amount. After $2 \mathrm{~h}$, the solvent was exchanged one more time and then the vial was kept overnight. Afterwards, the gel was washed 3 times with a small amount of solvent before dried in a vacuum oven (at $50{ }^{\circ} \mathrm{C}, 5 \mathrm{mbar}$ ) for at least $24 \mathrm{~h}$. The gel content was calculated following a formula:

Gel content $(\%)=\frac{m_{1}}{m_{0}} \times 100 \%$

Here, $m_{0}$ and $m_{1}(\mathrm{mg})$ are weight of a thin section before and after extracted with dichloromethane, respectively.

The experiment was done triplicates and results were averaged. From the collected solution of the gel consisting of $10 \mathrm{wt} \%$ HDDA the solvent was removed using a rotary evaporator at $25{ }^{\circ} \mathrm{C}$. Then, residues in the vial were dissolved in acetonitrile and characterised by high performance liquid chromatography (HPLC).
For light microscopic observation, a thin section of about $0.5 \mathrm{~mm}$ thickness was cut from the gel consisting of $10 \mathrm{wt} \%$ HDDA portion. The section was put on a petri dish which was placed under a light microscope (ZEISS AX10). To observe the extraction, dichloromethane was added to the petri dish. The whole experiment was recorded using a digital camera (Canon Powershot G12) which was connected to the light microscope. To observe swelling process, similar process was also done with a dried specimen from the gel content experiment.

\section{Storage stability test of the formulation and the gel}

To study pot-life of the gel formulations, an amount of $F P \_10 H D D A-B C P C$ and $F P \_20 H D D A-B C P C$ was collected right after preparation and stored at room temperature. Following a storage time, viscosity and NIR spectra of the formulations were measured. The viscosity measurement was done on a rheometer (Anton Paar MCR302 WESP) equipped with a PP25 measuring system. The measurement was conducted in rotation with a shear rate of $100 \mathrm{~s}^{-1}$ for the duration of $100 \mathrm{~s}$ at a constant temperature of $25^{\circ} \mathrm{C}$. For the analysis, the last viscosity value of this $100 \mathrm{~s}$ period was taken. All measurements were conducted in duplicates and the results were averaged. During the viscosity measurement, a NIR spectra of the formulation was recorded using Bruker Vertex 80 FT-IR spectrometer, in a range of $4000-7000 \mathrm{~cm}^{-1}$, a resolution of $8 \mathrm{~cm}^{-1}$ and 16 scans. The double bond and epoxy group conversion were calculated following the above equations Eqs. (1) and (2).

To study storage stability, the gel was stored in an oven at $50{ }^{\circ} \mathrm{C}$. Following a storage time, the NIR spectra were recorded for the gel at $25^{\circ} \mathrm{C}$. The epoxy group conversion was calculated following the above equation Eq. (1) to investigate the storage stability of the gel. RICFP was also carried out for the stored gels. The frontal parameters were measured and compared with those values of the fresh gel on day zero.

\section{Dynamic mechanical thermal analysis (DMTA)}

DMTA measurement was conducted for all above RICFP specimens. A cylinder specimen (diameter of about $4.6 \mathrm{~mm}$ ) obtaining from the above RICFP was cutoff irradiation part and polished to have a length of about $40 \mathrm{~mm}$. Then, this 40-mm long cylinder was polished both sides to have a symmetry shape with around $3 \mathrm{~mm}$ in thickness. The final specimen for DMTA was $40 \mathrm{~mm}$ long, $3 \mathrm{~mm}$ thick and $4.6 \mathrm{~mm}$ wide (Fig. S2, Supporting information). The measurement was done in torsion deformation, at an initial strain of $0.1 \%$ and a frequency of $1 \mathrm{~Hz}$. Two heating cycles were conducted for all measurements in a temperature range from -50 to 
$200{ }^{\circ} \mathrm{C}$ and a heating rate of $2{ }^{\circ} \mathrm{C} \mathrm{min}^{-1}$. The glass transition temperature $\left(T_{\mathrm{g}}\right)$ was defined as peak of the $\tan \delta$ curve.

\section{Preparation of RICFP-prepreg and its composites}

The formulation (FP_10HDDA-BCPC) consisting of $10 \mathrm{wt} \%$ of $H D D A-B C P C$ and $90 \mathrm{wt} \%$ of $F P$ was used for this study. RICFP-prepregs were prepared in a glass tube with an inner diameter of $6 \mathrm{~mm}$ and a length of $200 \mathrm{~mm}$. Carbon fibre tow was exactly weighed and inserted into the glass tube. Then, the formulation was transferred into the tube to impregnate the fibres using a syringe. Afterwards, the tube was closed at both sides and the formulation was gelled at $60{ }^{\circ} \mathrm{C}$, for $90 \mathrm{~min}$. Resultant RICFP-prepreg was collected by applying pressure air at one end of the tube. The procedure for preparation of the prepreg is illustrated in Fig. S3 (Supporting information). Fibre content was calculated as wt $\%$ by division of fibre weight to total weight of the prepreg.

For proof of concept, a composite with snowflake form was produced using RICFP-prepregs. The prepreg was cut to many segments with different lengths. Then, the segments were assembled together by hands. Owing to sticky surface, the snowflake form was remained (Fig. S4, Supporting information). There were 16 connecting points in the snowflake structure. The frontal polymerisation was initiated at the centre of the specimen using an UV light. The polymerisation process was recorded using a digital and an IR camera.

Acknowledgements We would like to thank the OeAD, the Ernst Mach Grant Asea-Uninet (funded by Bundesministerium für Wissenschaft, Forschung und Wirtschaft, No. ICM-2017-06830) and the Chemical Monthly Fellowship (funded by Österreichischen Akademie der Wissenschaften, No. 64870) for supporting this study.

Funding Open Access funding provided by TU Wien (TUW).

Open Access This article is licensed under a Creative Commons Attribution 4.0 International License, which permits use, sharing, adaptation, distribution and reproduction in any medium or format, as long as you give appropriate credit to the original author(s) and the source, provide a link to the Creative Commons licence, and indicate if changes were made. The images or other third party material in this article are included in the article's Creative Commons licence, unless indicated otherwise in a credit line to the material. If material is not included in the article's Creative Commons licence and your intended use is not permitted by statutory regulation or exceeds the permitted use, you will need to obtain permission directly from the copyright holder. To view a copy of this licence, visit http://creativecommons.org/licenses/by/4.0/.

\section{References}

1. Pansart S (2013) 6-prepreg processing of advanced fibre-reinforced polymer (FRP) composites. In: Bai J (ed) Advanced fibrereinforced polymer (FRP) composites for structural applications. Woodhead Publishing, Philadelphia, p 125
2. Hamerton I, Mooring L (2012) 7-the use of thermosets in aerospace applications. In: Guo Q (ed) Thermosets. Woodhead Publishing, Philadelphia, p 189

3. Ellis B (1993) Chemistry and technology of epoxy resins, 1st edn. Blackie Academic \& Professional, London

4. Pham HQ, Marks MJ (2004) Epoxy resins. Ullmann's encyclopedia of polymer science and technology. Wiley, Weinheim, p 1643

5. Stewart R (2012) Reinf Plast 56:18

6. Brøndsted P, Lilholt H, Lystrup A (2005) Annu Rev Mater Res 35:505

7. Javaid U, Ling C, Cardiff P (2020) Eng Fail Anal 116:104730

8. Prince K (2002) Reinf Plast $46: 48$

9. Composite developments drive auto industry forward (2014). Reinf Plast, p 22. https://doi.org/10.1016/S0034-3617(14)70135-3

10. Centea T, Grunenfelder LK, Nutt SR (2015) Compos A 70:132

11. Stewart AL, Poursartip A (2018) Compos A 112:239

12. Gopal KVN (2016) 14-product design for advanced composite materials in aerospace engineering. In: Rana S, Fangueiro R (eds) Advanced composite materials for aerospace engineering. Woodhead Publishing, Philadelphia, p 413

13. Fawaz Z (2016) 15-Quality control and testing methods for advanced composite materials in aerospace engineering. In: Rana S, Fangueiro R (eds) Advanced composite materials for aerospace engineering. Woodhead Publishing, Philadelphia, p 429

14. Pouladvand AR, Mortezaei M, Fattahi H, Amraei IA (2020) Compos A 132:105852

15. Ahn KJ, Peterson L, Seferis JC, Nowacki D, Zachmann HG (1992) J Appl Polym Sci 45:399

16. Hagnauer GL, Dunn DA (1981) J Appl Polym Sci 26:1837

17. Hayaty M, Honarkar H, Beheshty MH (2013) Iran Polym J 22:591

18. Fedtke M, Domaratius F, Pfitzmann A (1990) Polym Bull 23:381

19. Morgan RJ, Walkup CM, Hoheisel TH (1985) J Appl Polym Sci 30:289

20. George GA, Cash GA, Rintoul L (1996) Polym Int 41:169

21. Pojman JA (2012) 4.38-frontal polymerisation. In: Matyjaszewski K, Möller M (eds) Polymer science: a comprehensive reference. Elsevier, Amsterdam, p 957

22. Fiori S, Mariani A, Ricco L, Russo S (2003) Macromolecules 36:2674

23. Mariani A, Fiori S, Chekanov Y, Pojman JA (2001) Macromolecules 34:6539

24. Nason C, Roper T, Hoyle C, Pojman JA (2005) Macromolecules 38:5506

25. Uflyand IE, Zhinzhilo VA, Dzhardimalieva GI (2019) ChemistrySelect 4:2105

26. Ebner C, Mitterer J, Eigruber P, Stieger S, Riess G, Kern W (2020) Polymers 12:1291

27. Mariani A, Bidali S, Fiori S, Sangermano M, Malucelli G, Bongiovanni R, Priola A (2004) J Polym Sci Pol Chem 42:2066

28. Tran AD, Koch T, Knaack P, Liska R (2020) Compos Part A 132:105855. https://doi.org/10.1016/j.compositesa.2020.105855

29. Sangermano M, Antonazzo I, Sisca L, Carello M (2019) Polym Int 68:1662

30. Sangermano M, D’Anna A, Marro C, Klikovits N, Liska R (2018) Compos B 143:168

31. Bomze D, Knaack P, Koch T, Jin HF, Liska R (2016) J Polym Sci Pol Chem 54:3751

32. Bomze D, Knaack P, Liska R (2015) Polym Chem 6:8161

33. Knaack P, Klikovits N, Tran AD, Bomze D, Liska R (2019) J Polym Sci Pol Chem 57:1155

34. Klikovits N, Liska R, D’Anna A, Sangermano M (2017) Macromol Chem Phys 218:1700313

35. Kaur M, Srivastava AK (2002) J Macromol Sci Polym Rev 42:481

36. Nesvadba P (2012) Radical polymerisation in industry. In: Studer A (ed) Encyclopedia of radicals in chemistry, biology and materials. Major Reference Works. Wiley, New Jersey, p 1701 
37. Danso R, Hoedebecke B, Whang K, Sarrami S, Johnston A, Flipse S, Wong N, Rawls HR (2018) Dent Mater 34:1459

38. Fouassier JP, Lalevée J (2014) Polymers 6:2588

39. Nowers JR, Narasimhan B (2006) Polymer 47:1108

40. Decker C, Viet TNT, Decker D, Weber-Koehl E (2001) Polymer 42:5531

41. Polymerisation of monomers with organic peroxides. The Peroxide Company-PERGAN. https://www.pergan.com/files/downl oads/Polymerization_HP_EN.pdf. Accessed 14 Nov 2020

42. Applications: Free Radical Initiators. Sigma Aldrich. https://www. sigmaaldrich.com/content/dam/sigma-aldrich/docs/Aldrich/Gener al_Information/thermal_initiators.pdf. Accessed 14 Nov 2020

43. Gorsche C, Harikrishna R, Baudis S, Knaack P, Husar B, Laeuger J, Hoffmann H, Liska R (2017) Anal Chem 89:4958

44. Lachenal G, Pierre A, Poisson N (1996) Micron 27:329
45. Šašić S, Ozaki Y, Olinga A, Siesler HW (2002) Anal Chim Acta 452:265

46. Grabska J, Ishigaki M, Beć KB, Wójcik MJ, Ozaki Y (2017) J Phys Chem A 121:3437

47. Goli E, Robertson ID, Agarwal H, Pruitt EL, Grolman JM, Geubelle PH, Moore JS (2019) J Appl Polym Sci 136:47418

48. Robertson ID, Yourdkhani M, Centellas PJ, Aw JE, Ivanoff DG, Goli E, Lloyd EM, Dean LM, Sottos NR, Geubelle PH, Moore JS, White SR (2018) Nature 557:223

Publisher's Note Springer Nature remains neutral with regard to jurisdictional claims in published maps and institutional affiliations. 